\title{
NEGRITUDE, IDENTIDADE E DANÇA
}

Recebido em: 11/11/2021

Aprovado em: 06/12/2021

Licença: @) (1) @

\author{
Elisângela Chaves ${ }^{1}$ \\ Universidade Federal de Minas Gerais (UFMG) \\ Belo Horizonte - MG - Brasil
}

RESUMO: O presente artigo trata-se de um ensaio que busca articular negritude, identidade e dança como elementos constituintes e propulsores de práticas emancipadoras no âmbito da educação social e do lazer. O intuito foi explicitar a potencialidade que o ensino de danças de matriz afrodiaspórica têm ao serem abordadas em projetos educacionais socioculturais como mecanismo de empoderamento, valorização e identidade cultural junto a comunidades periféricas, em situação de vulnerabilidade social e cujos membros, em sua maioria, são negros. $\mathrm{O}$ ensino de dança em projetos socioculturais cresceu de forma vertiginosa nos últimos vinte anos no Brasil. Há uma evidente carência de dados para uma análise desse fato, o que dificulta a percepção da ampliação, da diversificação e do fortalecimento dessas alternativas de espaço para ensino/aprendizagem de danças que possibilitam tecnologias de resistência, sobrevivência e transformação na luta antirracista.

PALAVRAS-CHAVE: Dança. Educação social. Afrodiaspórico.

\section{BLACKNESS, IDENTITY AND DANCE}

ABSTRACT: This article is an essay that seeks to articulate blackness, identity and dance as constituent elements and drivers of emancipatory practices in the context of social education and leisure. The aim was to clarify the potential that the teaching of aphrodiasporic dances have when addressed in sociocultural educational projects as a mechanism for empowerment, appreciation and cultural identity with peripheral communities, in a situation of social vulnerability and whose members, in their majority, are black people. The teaching of dance in sociocultural projects has grown dramatically over the last twenty years in Brazil. There is an evident lack of data for an analysis of this fact, which makes it difficult to perceive the expansion, diversification and strengthening of these alternative spaces for teaching/learning dances that enable technologies of resistance, survival and transformation in the anti-racist struggle.

KEYWORDS: Dance. Social education. Aphrodiasporic.

\footnotetext{
${ }^{1}$ Docente da Universidade Federal de Minas Gerais e do Programa de Pós-graduação Interdisciplinar em Estudos do Lazer. Líder do grupo EduDança.
} 


\section{Introdução}

A atual conjuntura nos convoca a compreender e assumir a responsabilidade de nossas escolhas perante funções sociais e educacionais. Reconhecendo-me como uma mulher negra, mãe, dançarina, coreógrafa, professora e pesquisadora atuante em uma universidade pública, tenho buscado, nos últimos anos, uma reorganização de reflexões, ações e produções perante as pessoas, as instituições e a sociedade. A organização do mundo, como vemos hoje, restringe sentidos de existência perante os profundos desequilíbrios e a dificuldade do bem viver e exige análises conjunturais e pessoais sobre o que e como estamos agindo em prol de outras possibilidades, outras éticas de vida.

Adentrar essa seara nos aproxima potencialmente dos Estudos Culturais e das possibilidades interdisciplinares que podemos explorar nos campos de investigação e de ação pedagógica política. Na perspectiva de que a cultura é o lócus no qual se dão as disputas de saberes/conhecimentos/significações, assim como as representações acerca do mundo, das coisas e das pessoas, as regulações sociais precisam ser compreendidas a partir das relações de poder, tendo em vista uma determinada sociedade e um determinado tempo, uma vez que constituem as identidades, as diferenças e formas de ser/estar no mundo (HALL, 1997). É na tríade relacional entre os Estudos Culturais, do Lazer e da Dança que busco bases teóricas e empíricas comprometidas com a produção do conhecimento em prol das lutas de resistência étnico-racial, em especial da negritude, do antirracismo, da promoção da igualdade racial, da superação do colonialismo e do patriarcado.

O presente artigo configura-se como um ensaio que busca articular negritude, identidade e dança como elementos constituintes e propulsores de práticas emancipadoras no âmbito da educação social e do lazer, considerando suas mais 
diversas formas de existência, sistematização, intenções e propostas de atendimento a comunidades de baixa renda. Majoritariamente, essas comunidades ocupam espaços periféricos, marginalizados, com índices de qualidade de vida abaixo dos desejáveis, estando expostas a situações de vulnerabilidade social e econômica, além de serem compostas, em sua maioria, por população negra. A identidade dessa população é marcadamente distinguida a partir de preconceitos e discriminações socioculturais sobre a negritude. "Se historicamente a negritude é, sem dúvida, uma reação racial negra a uma agressão racial branca, não poderíamos entendê-la e cercá-la sem aproximá-la do racismo do qual é consequência e resultado”. (MUNANGA, 2020, p. 15).

Ações e reações antirracistas necessitam ser incisivas. O racismo é sempre mais duro com as pessoas que são suas vítimas diretas, mas, independentemente do pertencimento étnico-racial, ele imprime marcas negativas em todos nós, inclusive na construção dos processos identitários. Lutar contra o racismo exige a construção de estratégias, práticas, movimentos e políticas antirracistas concretas. É nesse sentido que esse artigo foi elaborado, com o intuito de explicitar a potencialidade do ensino de danças de matriz afrodiaspórica ao serem abordadas em projetos educacionais socioculturais como mecanismo de empoderamento, valorização e identidade cultural.

\section{Sobre Corpos, Dança e Negritude}

O corpo é amplamente discutido na contemporaneidade. Segundo Anne Suquet (2008, p. 538),

[...] através da exploração do corpo como matéria sensível e pensante, a dança do século XX não cessou de deslocar e confundir as fronteiras entre o consciente e o inconsciente, o "eu" e o outro, o interior e o exterior. E também participa plenamente na redefinição do sujeito contemporâneo. Ao longo do século, a dança contribuiu para desafiar a própria noção de corpo.

Historicamente, o corpo já foi visto como o suporte da mente e do espírito, mas, na atualidade, é entendido "como um conjunto que reúne pensamento e percepção, 
carne e abstração, sem que esses elementos sejam dicotômicos entre si, mas entendidos em um contexto cultural" (SIQUEIRA, 2006, p. 39).

A dança produz/reproduz codificações organizadas em grande escala, atitudes específicas em relação ao corpo e aos usos do corpo individualmente ou em grupos sociais específicos, coletivamente. Podemos perguntar quem dança, quando e onde, de que maneira, com quem e/ou com que finalidade? Ou ainda, nos perguntar quem não dança e por quê? Essa fluidez complexa nos provoca de diferentes formas, inclusive para ampliar nossa compreensão sobre a diversidade e as identidades sinalizadas, formadas, negociadas ou impostas também sobre os corpos, incluindo os que produzem, usufruem e fruem danças. A codificação de estilos performáticos e ancestrais, ligada às tradições ou aos ritos sociais, manifesta-se no corpo que dança e relaciona-se com as normas de expressão corporal dançada em contextos históricos e territoriais específicos (DESMOND, 2013).

Esse pensamento nos possibilita reflexões sobre várias questões igualmente importantes na contemporaneidade, vinculadas aos tensos e intensos debates sobre a colonialidade, as relações geracionais, as questões de gênero e sexualidade, de território, de etnia e raça, e as perspectivas decoloniais e interseccionais, tão caras aos Estudos Culturais e aos dilemas sociais atuais.

A matriz afrodiaspórica, tão presente em nossos ritos de festa, de religiosidade e de ludicidade, é um fato identitário na pluralidade de expressões da cultura no Brasil. O repertório de danças de matriz africana na cultura brasileira, ou seja, afro-brasileira, não se limita às manifestações recreativas de um grupo cultural. A referência a essas danças como forma de representação e identidade cultural brasileira faz parte do imaginário social, dos registros históricos, das prescrições curriculares sobre a cultura popular e o folclore, das representações de ancestralidade e de resistência das comunidades negras. 
A dança, como linguagem e expressão de um tempo e espaço, constitui uma das possibilidades de captação desse fato e dos embates identitários historicamente construídos. Nesse sentido, há de se questionar, tendo em vista uma perspectiva pósmoderna, se os espaços dos projetos socioculturais têm intencionalidade de produzir performances e estéticas de identidades resistentes à dominação eurocêntrica das epistemologias e das políticas. Parto da percepção de que um projeto que trabalhe com dança, concebido e/ou percebido na perspectiva da educação social, não se limita à formação da ou do dançarina/o profissional, mas também se atenta para o despertar dos seus alunos/as para "o conhecimento sobre o gosto e o prazer de dançar, que tanto pode ser sentido no próprio corpo, quanto na ampliação das possibilidades de assistir a outros corpos dançando" (GALVÃO SOUZA; PEREIRA; MELO, 2003, p. 151).

Entre a regulação e a emancipação, podemos inferir que, ao pensarmos símbolos culturais brasileiros, temos a nítida percepção da presença de elementos advindos da cultura africana, ressignificados a partir da diáspora escravista que constitui nossa história afro-brasileira, representada por uma trajetória marcada por violentas ações de submissão e apagamento de memórias. Como afirma Kabengele Munanga (2020, p. 16), “[...] a alienação do negro tem se realizado pela inferiorização do seu corpo antes de atingir a mente, o espírito, a história e a cultura."

A negação da corporeidade negra no contexto colonial e imperial brasileiro, que teve o escravismo como principal elemento para fazer funcionar a engrenagem econômica e social brasileira, persistiu no período pós-abolição e se faz presente até hoje, fundamentalmente, por meio do racismo e da desigualdade racial. As comunidades negras guardaram e produziram saberes sobre estéticas e corporeidades negras que foram sendo repassados, reelaborados, aprendidos e socializadados em âmbito local, global e nas culturas de massa. Nesse sentido, a obra de Nilma Lino Gomes (2017) é 
uma fonte de inspiração ao tratar a centralidade dos "saberes estético-corpóreos" produzidos pela comunidade negra e organizados pelas negras e pelos negros em movimento e nos movimentos negros de luta no combate ao racismo, integrando o que autora denomina de "movimento negro educador". Ainda segundo a autora, "esses saberes conseguiram algum nível de penetração social e participam da tensão histórica entre regulação e emancipação social" (GOMES, 2017, p. 80).

Entretanto, como nos alerta Sodré (2014), a corporeidade está entre os transes da globalização financeira do mundo. A consciência é corpórea e como tal nos desafia a questionar: que ordenamentos estamos seguindo nos processos educacionais implementados junto às comunidades negras e em prol de ações antirracistas?

\section{A Questão da Identidade}

Determinadas práticas específicas podem funcionar como marcadores de "diferença" social. Assim, as danças e seus sentidos e significados, no processo civilizatório ocidental, podem ser, em certa medida, reduzidos a um "estilo" e reposicionados marginalmente, por se tornarem contestatórias de uma prática do pensamento colonizador, do domínio das epistemologias do norte ou do epistemicídio. ${ }^{2}$ Essa possibilidade de redução é algo facilmente incorporado às expressões de dança, principalmente midiáticas, em suas várias dimensões na cultura. É preciso atenção crítica para a massificação e a manipulação dos indivíduos e da própria arte no hibridismo das culturas de massa. Mas, também, é preciso o reconhecimento da fluidez, dos escapes culturais, nem sempre alienantes, que as culturas de massa são capazes de produzir na intervenção, no empoderamento e na consciência individual e coletiva.

\footnotetext{
${ }^{2}$ Refiro-me à perspectiva conceitual de Boaventura de Souza Santos (2019) ao determinar que, para definir as epistemologias do sul, há de se referenciar o domínio das epistemologias do norte. Assim como o epistemicídio como processo de invisibilização e ocultação das contribuições culturais e sociais de povos subalternizados não assimiladas pelo 'saber' ocidental.
} 
A capacidade das releituras e derivações que as artes acessam na geração de estéticas outras é um dos pontos de resistência e de tensão para a luta contrahegemônica, inclusive antirracista. Não há dúvidas de que a arte na sociedade está sujeita a determinações econômicas (as relações interpessoais são determinadas pelos estágios de desenvolvimento das forças materiais produtivas), sociais (os significados e valores de uma classe dominante tendem a ser os formalizados pela arte) e políticas (a arte está sujeita a sofrer censuras ideológicas explicitas e veladas). Entre reprodução e produção, entre tradições e inovações, continuidades e rupturas, processos de violência, resistência e transgressão se expressam nas artes e nas práticas culturais, "em geral não apenas refletem essa situação determinante: elas também produzem significados e valores que entram ativamente na vida social, moldando seus rumos" (CEVASCO, 2003, p.112).

Podemos denominar essa dinâmica como um trajeto híbrido de identidades socioculturais. Esse hibridismo se traduz no corpo que dança, por meio de codificações e técnicas, em estilos performáticos e normas de expressão corporal que tanto podem simbolizar controle quanto liberdade, resistência ou aceitação, ruptura ou continuidade. Trata-se de contextos e mudanças históricas e geográficas específicas, em sistemas cinestésicos complexos, como, por exemplo, as crescentes e plurais manifestações de danças urbanas. ${ }^{3}$

O hibridismo está ligado aos movimentos demográficos, inclusive virtuais, que permitem o contato entre diferentes identidades, como as diásporas, os deslocamentos nômades, as viagens, os cruzamentos de fronteiras, as conexões virtuais pela internet. "Na perspectiva da teoria cultural contemporânea, esses movimentos podem ser literais,

\footnotetext{
3 O termo danças urbanas é usado para descrever danças que surgiram em contextos urbanos, que emergiram das ruas, parques, locais abertos, raves/festas e clubes. Reúnem vários estilos como: locking, wacking, vogue, popping, waving, scare crow, animation, boogalooing, hip hop, freestyle, house dance etc.
} 
como na histórica diáspora forçada dos povos africanos por meio da escravização, por exemplo, ou podem ser simplesmente metafóricos” (SILVA, 2000, p. 87).

Nos últimos anos, assim como em outros tempos, os grupos menorizados acabam por ocupar a margem da produção cultural em espaços e festivais artísticos regulares e consagrados. Esses grupos passíveis de vulnerabilidades lançam-se em esforços maiores em busca de validação das suas formas de representação e existência, lutando para não serem considerados meras formas de apropriação da diversidade ou para não serem manipulados pela mídia e por grupos detentores de poder.

A percepção e o reconhecimento da diversidade têm sido tema central em debates na área cultural, envolvendo tanto questões relacionadas ao empoderamento de representações estéticas, quanto ao posicionamento de grupos conservadores que censuram e vigiam as manifestações artísticas. Os limitados espaços que permitem e estimulam diálogos interculturais na relação com o diverso deparam-se com conflitos e desigualdades sociais na luta de grupos subalternos pela garantia de direitos básicos.

Infelizmente, temos assistido, na cena cultural e política brasileira, a ação de grupos com fins hegemônicos que abusam das relações de poder para violar a Constituição Brasileira, a liberdade de expressão, propagar o ódio e ignorar a existência das diferenças tão caras a um Estado democrático de direitos. Nesse sentido, são inúmeras as ações que representam retrocessos e reforços ao histórico ataque à eticidade das nossas relações, negando a diversidade e as diferenças que nos constituem como povo. Vivemos, na esfera política e civilizatória, um tempo de agressão aos direitos humanos, ambientais, culturais e sociais, por meio de uma onda de conservadorismo, de ataque à democracia e à existência da equidade. Os grupos identitários e os movimentos sociais (indígenas, LGBTQI+, negros e mulheres) estabelecem seus atos de resistência e militância, buscando o direito da representação de suas identidades singulares e 
coletivas consideradas minorias, entretanto, são vítimas de processos de opressão, exclusão e supressão de direitos básicos. Cabe-nos a busca de frestas, escapes, frentes de luta. Nesse sentido, a identificação do que nos é comum amplia possibilidades de fortalecimento e ação. A percepção da identidade cultural, entendida aqui como as particularidades que um indivíduo ou grupo atribui a si e o fazem sentir-se parte de algo, pode ser um imperativo de acolhimento e intervenção. "As identidades culturais são pontos de identificação, os pontos instáveis de identificação ou sutura, feitos no interior dos discursos da cultura e da história" (HALL, 1996, p. 70).

[...] a identidade de um grupo funciona como uma ideologia na medida em que permite a seus membros se definir em contraposição aos membros de outros grupos para reforçar a solidariedade existente entre eles, visando a conservação do grupo como entidade distinta. Mas pode também haver manipulação da consciência identitária por uma ideologia dominante quando considera a busca da identidade como um desejo separatista. Essa manipulação pode tomar a direção de uma folclorização pigmentada despojada de reinvindicação política (MUNANGA, 2020, p.13).

Assim, pluralmente, os movimentos negros vêm, ao longo do tempo, buscando brechas e formas de intervenção que qualifiquem suas lutas em prol da justiça social para população afrodescendente. $\mathrm{O}$ repertório de danças de matriz afrodiaspórica na cultura brasileira faz parte de um "todo social", do imaginário social, dos registros históricos, das prescrições curriculares sobre a cultura popular e o folclore, das representações de ancestralidade e resistência das comunidades negras. Mas, o fundamental nessa noção de todo social é a inclusão da noção de intenção. Nesse sentido, "a hegemonia nos permite ver como funciona e se processa a determinação da vida social pelas necessidades de uma classe dominante e de um modo preponderante de produção. Outra vantagem descritiva desse modelo é que prevê um sistema heterogêneo e em movimento" (CEVASCO, 2003, p.125-126).

É esse movimento que busco analisar, a partir da relação educação, cultura e lazer, focalizando as intencionalidades pedagógicas e artísticas em projetos 
socioculturais que adotam a dança como uma de suas intervenções para crianças e jovens. Abordar as identidades culturais propicia compreender como os indivíduos se autodescrevem e ambicionam viver seu presente e futuro. Trata-se da possibilidade de investigar tecnologias de resistência e superação de estigmas, preconceitos e discriminações. E, na perspectiva dos Estudos Culturais, a partir do materialismo cultural, é possível identificar uma fonte de organização do pensamento e da intervenção para uma educação crítica e emancipatória. Segundo Cevasco (2003),

\begin{abstract}
Além dos significados estabelecidos, o materialismo cultural busca ver no presente as sementes do futuro, de novos significados e novos valores que podem anunciar uma nova ordem social. Nesse sentido, é um dos recursos do que Williams chama de "uma jornada de esperança" (CEVASCO, 2003, p.116).
\end{abstract}

\title{
Arte e Educação
}

A pluralidade dos sistemas educacionais é uma dimensão fundamental para a garantia da educação como direito humano. Desde a aprovação da Declaração Universal dos Direitos Humanos pela Assembleia Geral das Nações Unidas, em 1948, em âmbito nacional ou internacional, temos vivido desafios e travado lutas para tornar acessíveis os direitos sociais que garantem o que chamamos de qualidade de vida, como o direito à educação, à moradia, à saúde, ao trabalho e ao lazer. Parte das violências ocasionadas pelo sistema capitalista, cada vez mais global, exacerbou desigualdades econômicas que contribuem para o aumento da intolerância e do autoritarismo, o que potencializa os deslocamentos humanos e a discriminação, além de desrespeitar, transgredir, menosprezar e incidir em prejuízos para a vida dos mais pobres. Esse movimento afeta um manancial de pessoas que, como define Boaventura de Sousa Santos (2019, p. 17), produzem e validam “[...] conhecimentos ancorados nas experiências de resistência de 
todos os grupos sociais que têm sido sistematicamente vítimas de injustiça, da opressão e da destruição causadas pelo capitalismo, pelo colonialismo e pelo patriarcado."4

Na busca pela superação de dificuldades, a educação ainda tem sido um campo de esperanças, ações e superações, principalmente para a população em situação de vulnerabilidade. Alternativas no campo da educação não formal tem sido um campo fértil de resistências e experimentações, assim como propostas outras, que atendam diferentes objetivos, desde a complementação da formação à retirada dos jovens das ruas, ações filantrópicas, educação profissionalizante, de lazer, organização comunitária, formação artístico cultural, movimentos sociais, educação social (MELO, 2008; CAMORS et al., 2016; PAULA, 2017).

Dentre as práticas consideradas educacionais, os esportes e as artes têm sido campos de investimento para prescrições e inovações educacionais no ensino não formal, embora, por vezes, sejam considerados como complementações e/ou extensões da formação infantojuvenil. A ampliação da jornada escolar, a ocupação do tempo livre e a complementação da formação são, no contexto da educação pública, as principais funções de atividades extraturno. E é no âmbito desse contexto que esse artigo se propõe a tematizar a potência dos saberes estéticos-corpóreos, termo cunhado por Nilma Lino Gomes (2017), de matriz afrodiaspórica. É na busca dessa materialidade corporificada em dança que serão estabelecidas reflexões sobre a educação social de crianças e jovens para conscientização e valorização da negritude, da identidade cultural e das ações antirracistas.

Melo (2006) destaca que tais propostas ajudam na valorização da arte como produção cultural na sociedade, na construção de diálogos entre os diferentes grupos

\footnotetext{
${ }^{4}$ A reflexão sobre o conhecimento importa a esta pesquisa e será ancorada na teorização de Boaventura sobre as epistemologias do Sul, que surgem das lutas sociais e políticas, que por vezes sequer são consideradas pelas epistemologias dominantes, mas são resistência contra opressão e ressignificam as experiências de conhecimento.
} 
sociais, inclusive nas comunidades de baixa renda. Dessa forma, a arte exerce função social ao permitir a crítica e a escolha como possibilidade para as pessoas. Ao ampliar, ao incomodar, as maneiras de ver a realidade; e educa para o desenvolvimento de um olhar cuidadoso dos signos e símbolos. E sobretudo quando "desencadeia vivências prazerosas (embora essas não devam ser consideradas como único padrão de julgamento: por vezes não é essa a intencionalidade do artista). Quando cumpre esses papéis, a arte extravasa sua existência para além da manifestação em si. Quando não, as obras podem não passar de algo amorfo para alguns, privilégio de uma minoria" (MELO, 2006, p. 36-37).

A dança é um texto cultural que reflete as condições, elementos e experiências culturais, tecnológicas e temáticas da sociedade. É uma forma de comunicação, uma linguagem que contém elementos universais e particulares ou específicos de uma dada cultura (SIQUEIRA, 2006, p. 73).

É nessa conexão cultural que dança, educação e lazer nos possibilitam a percepção de conflitos, tensões, contradições e complexidades. De manifestações tradicionais a inovações, do conformismo à resistência, encontramos na ambiguidade dos corpos dançantes a possibilidade da interpretação crítica da ordem social. Como nos explicita Christianne Gomes,

o lazer como necessidade humana e dimensão da cultura que se constitui na articulação de três elementos fundamentais: a ludicidade, as manifestações culturais e o tempo/espaço social. Tal necessidade pode ser satisfeita de múltiplas formas, segundo os valores e interesses dos sujeitos, grupos e instituições em cada contexto histórico, social e cultural. Nessa linha de interpretação, o lazer é uma prática social complexa que abarca uma multiplicidade de vivências culturais lúdicas contextualizadas e historicamente situadas (GOMES, 2014, p. 15).

Ludicidades e representações por intermédio da arte, da educação e do lazer são um tema relevante para o desenvolvimento de propostas políticas e educacionais que combatam as discriminações e exclusões, em um processo de aceitação e tolerância das diferenças para fortalecer e perpetuar os direitos sociais, as políticas públicas, as identidades culturais e as liberdades de expressão. Uma educação que englobe o 
respeito e a acessibilidade à diversidade cultural deve ser entendida como premissa de orientação para a mediação cultural.

A educação social articula várias áreas no processo educativo, como antropologia, sociologia, política, dentre outras. Seu objetivo central é produzir conhecimentos sobre os fenômenos educativos como caminhos para atender às necessidades das pessoas em vulnerabilidade social fora da escola formal. O livro Pedagogía social y educación social, de Camors et al. (2016), foi produzido por pesquisadores brasileiros e uruguaios que debateram essas temáticas com o intuito de promover um diálogo entre os pesquisadores da América Latina a respeito desses conceitos em construção. O conceito de educação social está “[...] indissociavelmente vinculado ao de exclusão,” (RIBEIRO, 2006, p. 160). Ribeiro (2006) destaca que há uma necessidade da educação social que decorre da exclusão social de crianças e jovens, da falta de condições mínimas de sobrevivência e, inversamente, a autora afirma que a educação social é potencializadora de alternativas para crianças e jovens excluídos socialmente. Tendo como foco a situação das comunidades negras brasileiras, as fragilidades são maiores e mais complexas. A interseccionalidade entre raça, classe social e gênero, no caso das meninas negras, amplia os prejuízos na formação e na socialização. Essa questão tem sido cada vez mais abordada no meio acadêmico e nos movimentos sociais que se posicionam contra essas desigualdades.

\footnotetext{
A universidade, os órgãos governamentais, sobretudo o Ministério da Educação, passam a tematizar mais sobre as desigualdades raciais. As pesquisas, as políticas educacionais e os indicadores de avaliação escolar começam a dar outro destaque à discussão sobre a questão racial. Os campos do direito e da justiça começam a ser pressionados para dar repostas que contemplem a concretização de uma sociedade igualitária que tenha como eixo o direito à diversidade. As tensões entre justiça social e desigualdades raciais começam a ocupar outro lugar nas preocupações e decisões jurídicas. O debate político sobre a raça traz à cena pública posições e situações que pensávamos superadas. Parte da imprensa começa a dar cobertura a algumas cenas de racismo que antes não eram assim consideradas, pois estavam naturalizadas em nosso imaginário social. As redes sociais reagem na internet, fazem circular abaixo-assinados e petições denunciando o racismo, o trato discriminatório e as distorções realizadas por setores poderosos da
} 
mídia, da academia e da política no que se refere a temas importantes da luta antirracista (GOMES, 2011, p. 47).

Dentre as várias técnicas e estéticas de dança em circulação, com expressiva manifestação nos projetos socioculturais, há resistência étnico-racial. E essa resistência manifesta nos corpos dançantes sentidos e significados dentro de um conjunto de estéticas performáticas, nos blocos de carnaval, nos grupos folclóricos, nos terreiros, nos bailes funk e nas batalhas de danças urbanas, que representam as manifestações não eurocêntricas e de matriz afro diaspórica. ${ }^{5}$

\section{Os Projetos Socioculturais e a Dança}

Os projetos socioculturais que investem no ensino/aprendizagem da dança como atividade e/ou conteúdo de sua intervenção pedagógica junto a crianças, adolescentes e jovens são um rico campo de percepção e análise. Trata-se de projetos desenvolvidos no âmbito da educação social e do lazer e que, em suas mais diversas formas de existência, sistematizam intenções e propostas para atender comunidades. A maioria dessas comunidades ocupam espaços periféricos marginalizados, com índices de qualidade de vida abaixo dos desejáveis, em situação de vulnerabilidade social e econômica e composta por uma população majoritariamente negra.

Esses projetos são iniciativas vinculadas aos governos e/ou à organização da sociedade civil que, com diferentes formas, intencionalidades e objetivos, têm nas práticas educacionais, esportivas e/ou artísticas suas principais ferramentas de intervenção social. O ensino de dança em projetos socioculturais cresceu de forma vertiginosa nos últimos vinte anos no Brasil. ${ }^{6}$ Há uma evidente carência de dados para

\footnotetext{
${ }^{5}$ Essas referências vinculam- se às práticas que identificam corporeidades advindas da africanidade e de seus hibridismos. Há de se considerar o multiculturalismo, a diversidade e a cultura de massa como elementos fundamentais para identificação dessas manifestações.

${ }^{6}$ Uma questão crucial para essa ampliação foi a criação de fomento via políticas públicas de cultura, esporte e lazer pelo Governo Federal do Brasil, pelos estados e municípios.
} 
uma análise desse fato, o que dificulta a percepção da ampliação, da diversificação e do fortalecimento dessas alternativas de espaço para ensino/aprendizagem de danças. Os trabalhos acadêmicos localizados, que publicizam experiências de dança em projetos versam sobre as trajetórias, as metodologias e outras especificidades de realidades únicas. ${ }^{7}$ Há uma nítida exposição de avanços e benesses dessas iniciativas para a formação, a educação e o empoderamento das comunidades que usufruem de projetos socioculturais. Em relação à dança, temos, no país, levantamentos sobre companhias de dança e escolas de formação profissional, embora haja poucos registros sobre a dimensão desses projetos de inclusão social que trabalham com a dança. Essa escassez de informação é uma questão importante para a análise de questões históricas, como a elitização do ensino de dança, fundada na colonialidade e na legitimação artística e social das danças de matriz eurocêntrica como a referência valorizada e disseminada com potencial estético, artístico e educacional, como o balé clássico.

A oferta volumosa de formação em dança nesses projetos de inclusão social, rompe a tradição do acesso à dança como proposta educacional elitista, vinculada às classes sociais abastadas. Percebe-se, também, que o ensino de danças, que outrora se limitava a escolas, academias, clubes, conservatórios e centros culturais, tem se constituído em grande volume nesses projetos que envolvem arte, esporte e lazer. Tais projetos representam iniciativas acessíveis a outras classes sociais que, não sendo privilegiadas pelo poder dominante, buscam produzir arranjos e mediações de resistência e formação de identidades de classe, de gênero, de geração e de etnias.

\footnotetext{
7 Ribeiro (2018, p. 123), ao analisar o Projeto Anjos da Rua, em Belo Horizonte - MG, reforça que "a articulação entre arte, cultura e educação mostrou-se um caminho possível e, na experiência analisada, a integração entre educador e educandos gerou uma significativa construção no coletivo. Tal discussão nutre nossa reflexão de como o indivíduo e os coletivos têm a possibilidade de conhecer e valorizar a pluralidade de expressões artísticas, em projetos socioculturais, ao usufruir dos equipamentos e dos espaços disponíveis para as práticas educacionais e lúdicas".
} 
Nas relações da vida cotidiana, na organização e no planejamento de cada projeto, há um pluralismo de métodos, estilos, técnicas e intencionalidades (GALVÃO SOUZA; PEREIRA; MELO, 2006).

Parte da bibliografia que expõe resultados e análises sobre o ensino/aprendizagem de danças em projetos socioculturais relata e sinaliza intervenções artísticas e pedagógicas capazes de transformar realidades de desfavorecimento econômico e social, de opressão e desigualdades, a partir da formação de uma consciência crítica coletiva.

Em 2021, o grupo de pesquisa EduDança-UFMG elaborou um estudo, ${ }^{8}$ em Belo Horizonte/ Minas Gerais/Brasil, com o objetivo de mapear e caracterizar os projetos socioculturais que trabalham com a dança para crianças e adolescentes na cidade. Esse levantamento não foi finalizado como planejado pelas/os pesquisadoras/es, devido à pandemia da covid-19 e às necessárias medidas de isolamento social, que fizeram com que a maioria das ações dos projetos fossem interrompidas e, apesar dos contatos e levantamentos de dados realizados, via on-line e por telefone, a cobertura total da cidade foi prejudicada em termos quantitativos.

Assim, o período pandêmico dificultou a cartografia da cidade, mas foi possível identificar projetos compatíveis com a intencionalidade pedagógica de interesse desta pesquisa. Dessa maneira, há um mapeamento de cerca de 30 projetos socioculturais que trabalham com dança e foram cadastrados, com informações sobre sua identificação, caracterização de técnicas/estéticas de dança trabalhadas, número de participantes, faixa etária, financiamento, formação dos professores, condições estruturais dos locais de aula, propostas pedagógicas, processos coreográficos e formas de funcionamento. Além do acesso à bases documentais, foram levantados contatos de professoras/es, artistas,

\footnotetext{
${ }^{8}$ Pesquisa desenvolvida pelo Grupo Edudança, em 2020 intitulada: Mapeamento do ensino de danças nos projetos sociais em Belo Horizonte- MG.
} 
animadoras/es e mediadoras/es culturais que realizam intervenções pedagógicas por meio da dança nesses projetos. O mapeamento possibilitou a identificação de estilos e técnicas apropriadas pelos projetos para o desenvolvimento das aulas e as montagens coreográficas em Belo Horizonte, de modo que foi possível identificar a expressiva quantidade de práticas de matriz afrodiaspórica.

Da mesma forma, Chaves e Silva (2019), ao mapearem as práticas de dança no Programa Esporte e Lazer na Cidade (PELC) ${ }^{9}$ revelaram uma realidade semelhante. A dança foi identificada como a segunda prática corporal mais escolhida pelos programas, de acordo com os registros de convênios cadastrados entre os anos de 2010 e 2014. Dos 160 convênios no território nacional, 142 (aproximadamente 88,7\%) apresentavam registros sobre a realização de práticas de dança de forma assistemática e/ou sistemática. Mas, ainda assim, há uma escassez de pesquisas sobre a dança em projetos socioculturais, dificultando, inclusive, o acesso a dados quantitativos.

Em 2016, por iniciativa do Ministério da Cultura (MinC), foi realizado o Mapeamento da Dança: diagnóstico da dança em oito capitais e cinco regiões do Brasil (MATOS; NUSSBAUMER, 2016). Esse mapeamento apresenta motivos acadêmico-políticos pouco convincentes para justificar a escolha das oito capitais selecionadas, bem como a exclusão de Belo Horizonte. Nesse sentido, o estudo revela uma leitura limitada da rede de produção em nível nacional e continua a não identificar a expansão de práticas de ensino de danças em instâncias não tradicionais. Ademais, ignora o fenômeno recente das organizações comunitárias, da criação de coletivos artísticos, das redes de cooperação, das ONGs e dos projetos em educação social

\footnotetext{
9 O Programa Esporte e Lazer na cidade (PELC), foi criado no Ministério do Esporte, por meio da Secretaria Nacional de Esporte, Educação, Lazer e Inclusão Social (SNELIS). Essa secretaria desenvolveu programas no âmbito do lazer que possuíam abrangência nacional, visando fomentar políticas públicas e sociais que atendessem à demanda da população, sobretudo daquelas em situação de vulnerabilidade social.
} 
financiados por governos e entidades privadas. Além disso, esse tipo de estudo e de abordagem ignoram que esse nicho de produção artístico-cultural, além de relações diretas com a educação social, tem influenciado a produção estética/performática, as metodologias de ensino e as caracterizações sobre a dança que se fazem no Brasil na atualidade.

No ano de 2006, a partir da proposta de um Sistema Nacional de Cultura no Brasil, foram instauradas uma série de medidas para conhecer, registrar e propor ações nacionais para a dança brasileira, dentre elas, a Pesquisa de Informações Básicas Municipais (MUNIC) do IBGE, 2006. A coleta de dados foi realizada nos municípios brasileiros a partir de três focos: fortalecimento institucional e gestão democrática; infraestrutura e recursos humanos; ações culturais. Esses dados, compilados pelo então Ministério da Cultura, foram reveladores para a área, identificou-se o fato de que a dança era a segunda manifestação artístico cultural mais disseminada no Brasil, ficando atrás apenas do artesanato (MATOS; NUSSBAUMER, 2016). Ou seja, o crescente movimento que emerge desses projetos tem sido negligenciado, apesar da nítida influência sobre a quantidade de aprendizes/praticantes de dança, a formação profissional de dançarinos e a produção artístico-cultural periférica (economia), que geram impactos a serem desvelados e contextualizados no cenário nacional da produção artística em dança. Esse cenário inspira reflexões, como: que sentidos e significados configuram essa forma de expressão e de linguagem para a identidade cultural da juventude? Que saberes estético-corpóreos alusivos à negritude ${ }^{10}$ são discriminados e construídos nessas práticas?

\footnotetext{
${ }^{10}$ Referência à designação de Nilma Lino Gomes (2017), ao destacar a constelação de saberes produzidos pelos negros no Brasil em: saberes identitários, saberes políticos e saberes estético corpóreos. Saberes que realidades social, cultural, política e econômica se constroem de forma articulada e imbricada.
} 


\section{Considerações Finais}

O fato de um projeto de dança estar organizado em uma determinada comunidade de baixa renda por si só não garante que ele seja "social", efetivo e/ou de qualidade ou que o debate sobre a dança ali realizado se aproxime de dinâmicas no âmbito da educação social e contribua para a formação de uma sociedade mais justa, sem preconceitos, estereótipos e discriminações. Nesse sentido, algumas perguntas orientam esta reflexão sobre a dança como uma intervenção pedagógica no âmbito de projetos socioculturais. Os saberes estéticos/corpóreos, a corporeidade, o corpo em movimento, são uma grande potência para a dança de identidade cultural da negritude. Como diz Sodré (2014),

O culturalismo lúdico que investiu o espaço público desde fỉns da primeira metade do século passado, por efeito do desenvolvimento acelerado das tecnologias da comunicação incita a pedagogia contemporânea a alinhar-se com a oferta estética de meios expressivos como a música, a dança, o cinema e o teatro (SODRÉ, 2014, p.14).

Não podemos desconsiderar essa potência para o empoderamento e a valorização identitária das comunidades que se organizam no cotidiano de desfavorecimentos para educação e o lazer das crianças e jovens periféricos. Há de se considerar essas ações e intencionalidades como tecnologias de resistência, sobrevivência e transformação na luta antirracista.

A identidade do mundo negro se apresenta sob a forma de exclusão, ser negro é ser, de alguma forma, excluído. A educação social, intencionalmente inclusiva, tem nos mostrado possibilidades de enfrentamento. A dança, assim como outras práticas artístico-culturais e esportivas, performatiza saberes estético-corpóreos de nossas matrizes afrodiaspóricas como um sinal de que luta e beleza podem ser revolucionários em diferentes tempos e espaços. 


\section{REFERÊNCIAS}

CAMORS, J. et al. Reflexiones sobre las prácticas educativas en Brasil y Uruguai: pedagogia social y educacional social. 1 ed. Uruguay: Unidad de Medios Técnicos, Ediciones y Comunicación (UMTEC), 2016.

CEVASCO, M. E. Dez lições sobre Estudos Culturais. São Paulo, SP: Boitempo, 2003.

CHAVES, E.; SILVA, N. O. Dança e Identidade Cultural: reflexões sobre o Pelc. In: ENCONTRO INTERNACIONAL OTIUM, 12 E CONGRESSO INTERNACIONAL EM ESTUDOS CULTURAIS, 6. Associação Ibero-americana de Estudos de Ócio-Rede OTIUM. Anais... Aveiro- PT, 2019.

DECLARAÇÃO UNIVERSAL DOS DIREITOS HUMANOS. 1948. Disponível em: https://www.unicef.org/brazil/declaracao-universal-dos-direitos-humanos. Acesso em: 15 set. 2021.

DESMOND, J. C. Corporalizando a diferença: questões entre Dança e Estudos Culturais. Revista Dança, Salvador- BA, v. 2, n. 2, p. 93-120, jul./dez. 2013.

GALVÃO, S. M. I.; PEREIRA, P. G.; MELO, V. A. Dança e animação cultural: “improvisações”. Pensar a Prática, Goiânia, v. 6, p. 139-156, nov. 2006. Disponível em: https://www.revistas.ufg.br/fef/article/view/60. Acesso em: 10 set. 2021.

GOMES, C. L. Lazer: necessidade humana e dimensão da cultura. Revista Brasileira de Estudos do Lazer. v. 1, n.1, p.3-20, jan./abr. 2014.

GOMES, N. L. O movimento negro educador: saberes construídos nas lutas por emancipação. Petrópolis: Vozes, 2017.

GOMES, N. L. Movimento negro, saberes e a tensão regulação-emancipação do corpo e da corporeidade negra. Contemporânea, n. 2, p. 37-60, Jul/Dez. 2011.

HALL, S. Identidade cultural e diáspora. IPHAN: Revista do Patrimônio Histórico e Artístico Nacional, Rio de Janeiro, p. 68-75, 1996. Disponível em: https://portalseer.ufba.br/index.php/revistadanca/issue/view/894/showToc. Acesso em: 10 nov. 2021.

HALL, S. (Org.). Representation: cultural representations and signifying practices. London/Thousand Oaks/New Delhi: Sage/Open University, 1997.

MATOS, L.; NUSSBAUMER, G. (Coord.) Mapeamento da dança: diagnóstico da dança em oito capitais de cinco regiões do Brasil. Salvador: UFBA, 2016.

MELO, V. A. de. Animação cultural: conceitos e experiências. Campinas: Papirus, 2006.

MELO, V. A. "Projetos socioculturais" de esporte e lazer: reflexões, inquietações, sugestões. Quaderns d'Animació i Educació Social, Valencia, España, n. 7, enero, 2008. Disponível em: http:quadernsanimacio.net. Acesso em: 3 maio 2018. 
MUNANGA, Kabengele. Negritude: usos e sentidos. 4.ed. Belo Horizonte: Autêntica, 2020.

PAULA, J. A. "Isso dá para aprender!": a dança na educação integral. 2017. 89f. Dissertação (Mestrado em Educação) - Faculdade de Educação, Universidade Federal de Minas Gerais, Belo Horizonte, 2017.

RIBEIRO, Marlene. Exclusão e educação social: conceitos em superfície e fundo. Educação \& Sociedade [online]. v. 27, n. 94, p. 155-178, 2006. Disponível em: https://doi.org/10.1590/S0101-73302006000100008. Acesso em 13 Dez. 2021. Epub 29 Maio 2006. ISSN 1678-4626.

RIBEIRO, B. C. R. O. O ensino da dança em um projeto social do Programa Escola Aberta: questões para a construção do conhecimento e currículos pelo viés da educação somática. 2018. Dissertação (Mestrado em Educação) - Faculdade de Educação, Pontifícia Universidade Católica de Minas Gerais, Belo Horizonte, 2018.

SANTOS, B. V. de S. O fim do império cognitivo. Belo Horizonte: Autêntica, 2019.

SILVA, T. T. da (Org). Identidade e diferença: a perspectiva dos estudos culturais. Petrópolis, RJ: Vozes, 2000.

SIQUEIRA, D. da C. O. Corpo, comunicação e cultura: a dança contemporânea em cena. Campinas: Autores Associados, 2006.

SODRÉ, M. Cultura, corpo e afeto. Revista Dança, Salvador, v. 3, n. 1, p. 10-20, jan./jul. 2014.

SUQUET, Anne. Cenas - o corpo dançante: um laboratório da percepção. In: COURTINE, Jean- Jacques; VIGARELLO, Georges; CORBIN, Alain. História do Corpo. As mutações do olhar, o século XX- Introdução. Petrópolis-RJ: Vozes, 2008.

\section{Endereço da Autora:}

Elisângela Chaves

Endereço Eletrônico: elischaves@ hotmail.com 